and full of birds." Here one of the great discoveries of the second expedition was made, which is described by the author in his usual lively manner:-

"The gale continued next day with rain, until noon, when I took advantage of our enforced delay, and went on shore for a few hours. A climb of about roo feet brought me on to the tundra. In some places the cliffs were very steep, and were naked mud or clay. In others the slope was more gradual, and covered with willow and alder bushes. In these trees Thrushes were breeding. I soon found the nest of a Dusky Ouzel, with five nearly fledged young. It was placed as before in the fork of a willow, level with the ground. On the top of the bank I found myself on the real Tundra. Not a trace of a pine tree was visible, and the birch trees rarely exceeded twelve inches in height. There was less grass, more moss and lichen, and the ground was covered with patches of yellow mud or clay, in which were a few small stones, that were apparently too barren for even moss or lichen to grow upon. The Tundra was hilly, with lakes, swamps, and bogs in the wide valleys and plains.

"As soon as I reached the flat bogs I heard the plaintive cry of a Plover, and presently caught sight of two birds. The male was very conspicuous, but all my attempts to follow the female with my glass, in order to trace her to the nest, proved ineffectual, she was too nearly the colour of the ground, and the herbage was too high. Feeling convinced that I was within thirty paces of the nest, I shot the male, and commenced a diligent search. The bird proved to be the Asiatic Golden Plover, with gray axillaries, and I determined to devote at least an hour looking for the nest. By a wonderful piece of good fortune I found it, with four eggs, in less than five minutes. It was merely a hollow in the ground upon a piece of turfy land, overgrown with moss and lichen, and was lined with broken stalks of reindeer moss. The eggs resembled more those of the Golden than those of the Grey Plover, but were smaller than either.

"These are the only authenticated eggs of this species known in collections."

Golcheeka, the port at the mouth of the Yenesay, was reached on July 18. As Mr. Seebohm did not think it prudent to attempt the sea-passage home in the little Ibis, and the last steamer of the season up the Yenesay was to leave six days afterwards, little could be done in this locality. But excursions were made over the adjoining tundra, where "birds were abundant." "Golden Plovers, Arctic Terns, Ruffs, Red-necked Phalaropes, Snow-buntings, Lapland Buntings, and Dunlins were continually in sight, and the Asiatic Golden Plover was breeding in numbers, though attempts to watch them on to their nests were made in vain." On July $24 \mathrm{Mr}$. Seebohm finally turned his face homewards, and reached Yenesaisk on August I4, after twenty-two days on the road, which was considered "a good pas sage." Thence post-horses, steamers, and railways brought him back to Sheffield on October I5, after a journey of some i 5,000 miles.

The ornithological results of the second journey were "on the whole satisfactory." It was a great disappointment not to get to the coast, and still more so to miss the birds of the Kara Sea, and to arrive on the tundra too late for most of the eggs specially sought for. This misfortune was caused by the wreck of the Thames. But on the other hand "the delay in the pine-forests produced some very interesting results." Besides the eggs of the Asiatic Golden Plover already spoken of, nests and eggs of three species of Willow-warblers, of the MountainAccentor, of the Little Bunting, and of the Red-breasted Goose were obtained. All these were previously unknown to western collectors, and were for the most part never previously obtained. Besides this, a large number of other rare birds were found nesting, their eggs and young plumages obtained, and their habits and manners studied and recorded. Concerning particulars of their discoveries, and for much information on the native tribes of Northern Siberia (a subject to which our author appears to have devoted great attention), as likewise for observations on every other incident coming before the eyes of an intelligent traveller during a journey of 15,000 miles, we must refer our readers to Mr. Seebohm's volumes, which are full of interest not only to ornithologists, but to those who take pleasure in natural history in its widest extent. They may be placed on our shelves next to Bates's "Amazons" and Wallace's "Eastern Archipelago," and form no unworthy companions to the works of those great naturalists.

\section{THE BACILLUS OF TUBERCLE}

M R. WATSON CHEYNE'S Report on the Relation of Micro-organisms to Tuberculosis, published in the Practitioner for the present month, is one of the fruits of the Association for the Advancement of Medicine by Research, recently constituted for the protection of working physiologists and pathologists. On commission from the Association, Mr. Cheyne visited two of the chief workers on this subject, Toussaint and Koch. He was thus able to see their methods and obtained materials from them with which he has experimented on his return to England.

After some remarks on the method of staining the tubercle bacillus, Mr. Cheyne describes some experiments made with the view of testing the theory that tuberculosis in rodents can be induced by almost any irritant. The result of these experiments, made on a considerable number of animals, was to disprove this theory and to lead to the conclusion that in the former experiments, made before our present knowledge as to the precautions necessary for disinfection of instruments, \&c., was gained, the channels for the introduction of specific microorganisms had been left unguarded.

Experiments were next made to test Toussaint's statement that micrococci can be cultivated from the blood of tuberculous animals, and that the injection of these micrococci into other animals is often followed by tuberculosis. Mr. Cheyne failed to cultivate micrococci from the blood of tuberculous animals; he injected micrococci which M. Toussaint had liberally placed at his disposal, into a considerable number of animals without result, and he found tubercle-bacilli but no micrococci in the organs of several animals which had been injected by Toussaint himself with micrococcal fluid, and had become tuberculous. He therefore concludes that Toussaint's micrococci do not cause tuberculosis, and that an error has crept into his experiments probably because the means used to disinfect his syringes, although amply sufficient to destroy some other kinds of bacilli, did not destroy the tubercle-bacilli.

Cultivations of bacilli were also obtained from Dr. Koch, and the results of their inoculation was in all cases rapid development of tuberculosis. The examination of a large quantity of tuberculous material showed the constant presence of tubercle-bacilli, but of no other microorganisms. The rapidity and certainty of action of tuberculous material when inoculated into animals was in direct ratio to the number of bacilli introduced, and the most certain and rapid means of inducing tuberculosis in animals is the inoculation of the tubercle-bacillus cultivated on solidified blood-serum. These facts lead Mr. Cheyne to the conclusion that we have before us in these bacilli the virus of the acute tuberculosis caused in animals by the inoculation of tuberculous material.

Pursuing the inquiry from this point, to which it had been brought by the researches of Koch, Mr. Cheyne proceeds to discuss the relation of these bacilli to tuberculous processes in man and to tubercle generally. In all tubercles there are present epithelioid cells, to which, 
however, only a few authors have attached any importance. On investigation $\mathrm{Mr}$. Cheyne found that the tubercle-bacilli were, unless when present in large numbers, only found in or among these epithelioid cells, and that the tuberculous nodules first begin by the entrance of bacilli into these cells and the subsequent development of the epithelioid elements. Surrounding these epithelioid cells a slight amount of inflammation occurs, giving rise to the small-celled growth around the tubercle, which is generally regarded as the growing part of the tubercle. This Mr. Cheyne denies, asserting that it is merely inflammatory tissue, and that the essential elements of the tubercle are the epithelioid elements in its centre. In the lungs these cells seem to be derived from the alveolar epithelium, in the liver of en apparently from the liver cells, but in other organs and also sometimes in these from the endothelium of the lymphatics and blood-vessels.

In phthisis the bacilli were found at the margin of cavities and in the epithelioid cells surrounding the cheesy matter. Mr. Cheyne concludes that in phthisis the bacilli, inhaled into the alveoli, develop in the alveolar epithelium, cause accumulation of epithelial cells in the alveolus, and inflammatory hypertrophy of its walls. Thus the bacilli are practically shut off from the circulation and acute general tuberculosis cannot occur. The two extremes of phthisis are considered - the very rapic form or caseous pneumonia, and the slow form or fibroid phthisis. In the former the bacilli grow rapidly, are fairly numerous, and the lung rapidly breaks down; in the latter the bacilli grow slowly and with difficulty, and hence extensive fibrous formation occurs.

There are many other points of interest in this research to which we caunot allude, but which will be found at length in the Report. The Association is to be congratulated on having chosen such a fertile subject for their first report, and we hope that they will continue to encourage similar work.

PROFESSOR H. J. S. SMITH AND THE REPRESENTATION OF A NUMBER AS A SUM OF $S Q U A R E S$

THE award of the great Mathematical Prize of the French Academy to the late Prof. H. J. S. Smith may have the effect of drawing the attention of mathematicians to the wonderful extent and value of his researches on the Theory of Numbers. Probably no more important or remarkable mathematical investigations have ever appeared in this country than his memoirs on systems of linear indeterminate equations and congruences and on the orders and genera of ternary quadratic forms and of quadratic forms containing more than three indeterminates, which were published in the Philosophical Transactions for $186 \mathrm{I}$ and 1867 and the Proceedings of the Royal Society for 1864 and 1867 . The results contained in these papers are by far the greatest additions that have been made to the Theory of Numbers since it was placed on its present foundation by Gauss in the "Disquisitiones Arithmeticæ." The subject for which the prize was awarded to Prof. Smith was that of the theory of the representation of a number as a sum of five squares, and of this question as well as that of the corresponding one for seven squares he had given the complete solution in the Proceedings of the Royal Society tor I 867 (vol. xvi. p. 207). The words with which Prof. Smith introduced his statement of the solution of these important questions are as follows:-

"The theorems which have been given by Jacobi, Eisenstein, and recently in great profusion by M. Liouville, relating to the representation of numbers by four squares and other simple quadratic forms, appear to be deducible by a uniform method from the principles indicated in this paper. So also are the theorems relating to the representation of numbers by six and eight squares, which are implicitly contained in the developments given by Jacobi in the 'Fundamenta Nova.' As the series of theorems relating to the representation of numbers by sums of squares ceases, for the reason assigned by Eisenstein, when the number of squares surpasses eight, it is of some importance to complete it. The only cases which have not been fully considered are those of five and seven squares. The principal theorems relating to the case of five squares have indeed been given by Eisenstein (Crelle's Journal, vol. xxxv. p. 368); but he has considered only those numbers which are not divisible by any square. We shall here complete his enunciation of those theorems, and shall add the corresponding theorems for the case of seven squares."

In the announcement of the subject for the prize in the Comptes Rendus in February of last year, reference was made to the work of Eisenstein, but the fact that his solution had fifteen years before been completed by Prof. Smith - who had also solved the problem in the case of seven squares, the whole being only a corollary from the general principles contained in his memoir - seems to have escaped the attention of the propcsers of the subject. In the paper in the Proceedings of the Royal Society the results only for the case of five squares and seven squares are given, the demonstrations being omitted; and accordingly, when the subject for the prize was announced, Prof. Smith followed the only course open to him, and communicated to the Academy his demonstrations for the case of five squares.

All who knew Prof. Smith will understand how uncongenial to him was the idea of becoming a competitor for the prize, but under the circumstances he had no choice. It is a singular tribute to Prof. Smith's mathematical powers, as well as a curious episode in the history of mathenatics, that the French Academy should have chosen as the subject of the "Grand Prix"--thereby indicating their opinion of its importance in the advance of the science ${ }^{1}-$ a question that had been solved already fifteen years before as a corollary from more general principles.

The state of the question of the number of ways in which a number can be expressed as a sum of squares therefore stands as follows:-For two squares the solution was given by Gauss in the "Disquisitiones"; the cases of four, six, and eight squares are due to Jacobi, Eisenstein, and Prof. Smith (see Report of the British Association for I865, p. 366). In these cases in which the nu.nber of squares is even, the problem can be solved by means of elliptic functions, and it is not necessary to have recourse to the special methods of the Theory of Numbers; but it is not so in the case when the number of squares is uneven, and the question is then essentially "arithmetical" as regards its method of treatment and expression. The case of three squares was given by Lejeune-Dirichlet, and is included in Prof. Smith's general treatment of ternary quadratic forms in the Philosophical Transactions for 1867: the enunciations for the cases of five squares and seven squares were given, as has been stated, in the Proceedings of the Royal Society for 1867. The demonstrations for the case of five squares have been communicated to the French Academy, but those for seven squares still remain unpublished in Prof. Smith's note-book. This class of questions ceases to admit of the same kind of solution when the number of squares exceeds eight, so that with the publication of the demonstrations for seven squares the solution of the whole problem will be complete. It will be seen that Prof. Smith has had a large share in this great mathematical victory.

I “'L'Académie était donc fo.dée à espérer que ce voyage de découvertes imposé aux concurrents à travers une des régions les plus intéressantes et les mons explorées de l'arithmétique produirait des résultats féc ınds pour la science. Cette attente n'a pas été trompée." Report on the award of the prize. Comptes Rendus, April 2, 1883. In this report however no mention is made of the fact that these "résultats fÉconds" had been published in 1867 . 